\title{
Role of nerve ultrasound versus electrophysiological studies in the evaluation of nerve injuries
}

\author{
Neveen Mohamed Elfayoumy ${ }^{1}$, Hanan Helmy Elgendy ${ }^{2}$, Marwa Saad Afify Saad ${ }^{1}$ and Amira A. Labib ${ }^{1,3^{*}}$
}

\begin{abstract}
Background: High-resolution ultrasonography (US) is a non-invasive, readily applicable imaging modality capable of depicting real-time static and dynamic information concerning the peripheral nerves and their surrounding tissues. Although electrophysiological studies are the gold standard in the evaluation of nerve injuries, US can be used also to evaluate the morphological changes of nerve injuries.
\end{abstract}

Objectives: To evaluate the role of the high-resolution US in the assessment of nerve injuries and to compare it to the role of electrodiagnostic studies.

Subjects and methods: A total of 30 nerves from 22 consecutive patients with clinically definite nerve injury were considered. Two independent and blinded clinicians perform electrodiagnosis and US. The clinical, neurophysiological, and US findings were collected, and the contribution of US was then classified as " contributive" or "non-contributive", according to whether US confirmed the clinical and neurophysiological diagnosis or not.

Results: US was "contributive" (confirming the electrophysiological diagnosis) in $66.67 \%$ of cases $(n=20)$, providing information about continuity of the nerve, morphological changes after injury as swelling, scar tissue formation, or neuroma formation with sensitivity of $75 \%$ compared to the electrodiagnostic studies and accuracy of $66.67 \%$.

Conclusion: Ultrasound can be used, when available, as a complementary tool for electrodiagnostic studies to provide anatomical information about the injured nerves in case of complete axonal lesion.

Keywords: Nerve injuries, Electrodiagnostic studies, Ultrasonography

\section{Introduction}

Traumatic peripheral nerve injuries are common in clinical practice. The type of peripheral nerve injury is a key factor for determining optimal treatment [1].

Though clinical evaluation and electrophysiological studies remain a mainstay in the initial detection and diagnosis of peripheral nerve pathologies, US is playing complementary and growing roles in the overall clinical

\footnotetext{
* Correspondence: amira.labib@kasralainy.edu.eg

'Clinical Neurophysiology Unit, Faculty of Medicine, Cairo University, Cairo, Egypt

${ }^{3}$ Kasr Al Ainy, Faculty of Medicine, Cairo University, 52 Mosadak Street, Dokki,

Giza 12611, Egypt

Full list of author information is available at the end of the article
}

workup, localizing focal injury and entrapment and potentially obviating invasive nerve conduction studies [2].

Electrophysiology is still the clinical "gold standard" for nerve assessment, but rapidly accumulating literature exist comparing this modality with US. While electrophysiological studies provide important diagnostic data in evaluating the relative location and degree of nerve dysfunction, they are limited in their ability to identify morphological changes associated with a particular type of nerve injury. US can reliably provide this information, and it does so in a painless manner, as compared to electrodiagnostic studies [3].

\section{Springer Open}

(c) The Author(s). 2020 Open Access This article is licensed under a Creative Commons Attribution 4.0 International License, which permits use, sharing, adaptation, distribution and reproduction in any medium or format, as long as you give appropriate credit to the original author(s) and the source, provide a link to the Creative Commons licence, and indicate if changes were made. The images or other third party material in this article are included in the article's Creative Commons licence, unless indicated otherwise in a credit line to the material. If material is not included in the article's Creative Commons licence and your intended use is not permitted by statutory regulation or exceeds the permitted use, you will need to obtain permission directly from the copyright holder. To view a copy of this licence, visit http://creativecommons.org/licenses/by/4.0/. 


\section{Subjects and methods}

This is a cross-sectional study that was carried out on 30 nerves of 22 patients with history of peripheral nerve injuries. They were recruited from the clinical neurophysiology unit at Kasr Al Ainy hospitals, Cairo University. All of them gave informed consent to the study. The study included both genders, with an age range between 16 and 59 years. They all had a clinical picture of peripheral nerve injury in the upper or lower limbs of less than 2 months duration. We excluded patients with diabetes mellitus, polyneuropathies, renal or hepatic disorders, or radiculopathy (clinical or electrophysiological in the segment supplying the injured nerve).

All patients were subjected to thorough history taking and clinical examination of the limbs to detect the motor manifestations especially weakness or atrophy. Power of the muscles was examined according to the Medical Research Council (MRC) scale (Appendix 1).

The electrophysiological studies were carried out using Nihon Kohden; Neuropak MEB-9200G/K EP/EMG measuring system (Neuropak M1) version 08.1, Japan. Routine motor nerve conduction studies (NCS) recording from the injured nerve were abductor pollicis brevis; stimulating wrist and ante-cubital fossa for median nerve, abductor digiti minimi; stimulating wrist, below and above elbow for the ulnar nerve, extensor indicis proprius; stimulating forearm and elbow for the radial nerve and extensor digitorum brevis; stimulating ankle, below and above neck of fibula for the peroneal nerve.

Routine sensory NCS recording second digit (antidromic stimulation at wrist for the median nerve), fifth digit (antidromic stimulation at wrist for the ulnar nerve), anatomical snuff box (antidromic stimulation at wrist for the superficial radial nerve) and ankle $14 \mathrm{~cm}$ proximally in the anterolateral side of the leg for the superficial peroneal nerve.

Needle electromyography (EMG) was performed for the muscles supplied by the affected nerve using concentric needle, starting distally then proximally for leveling of the injury. EMG examination was also performed for the adjacent muscles to exclude multiple nerve injuries.

The sonographer was blinded for clinical and neurophysiologic results. The studies were performed with a high-frequency $5-17-\mathrm{MHz}$ linear probe of a Philips Diagnostic US System (model iU22), Canada. Ultrasonographic examination was performed also to the normal unaffected side to compare the normal and injured nerves. The normal and injured nerves were visualized in longitudinal and transverse planes to confirm identification of the nerve. The shape of the injured nerve was determined if there was neuroma, fibrosis, edema, or distortion of the nerve. The cross-sectional area (CSA) of the nerve was measured proximal to the site of the injury. It was measured by means of a direct tracing method using the inner margin of the hyperechoic sheath as the margin of the nerve. We searched for the continuity of the nerve, presence or absence of fibrosis, distortion, or neuroma formation.

\section{Statistical methods}

Data were coded and entered using the statistical package SPSS, version 25; SPSS Inc., Chicago, IL, USA, for the year 2017. Numerical data were summarized using means and standard deviations or medians and ranges. Data were explored for normality using KolmogorovSmirnov test and Shapiro-Wilk test. Categorical data were summarized as percentages. Comparisons between the two groups with respect to normally distributed numeric variables were done using the independent $t$ test. Non-normally distributed numeric variables were compared by Mann-Whitney test. For categorical variables, differences were analyzed with $\chi^{2}$ (chi-square). ANOVA test were used to compare three groups (shape of nerve). Spearman rho correlation was used to assess correlation between different variables. All $p$ values were two-sided and values $\leq 0.05$ were considered significant.

\section{Results}

The age of the subjects ranged from 16 to 53 years, with a mean age of $28.8 \pm 11.1$ years. There were 21 males (95.5\%) and 1 female (4.5\%). The duration of injury of the involved nerves ranged between 20 and 60 days, with a mean of $47.1 \pm 12.2$ days.

We examined the sensation of 30 nerves and the power of the muscles supplied by these nerves. Results are shown in Table 1.

Nerve trauma was caused in the majority of cases by cut injury. These constituted 20 nerves, $66.7 \%$ of the total involved nerves. The remaining injured nerves were caused by limb traction (16.7\%), post-operative injury (6.7\%), after fractures (6.7\%), and compression injury (3.3\%). Results of NCS and EMG are shown in Table 2.

Table 1 Power of the muscles and sensations of the dermatomes of the affected nerves

\begin{tabular}{lll}
\hline & Number of nerves & Percentage \\
\hline 0 & 17 & 56.7 \\
2 & 4 & 13.3 \\
3 & 6 & 20.0 \\
4 & 3 & 10.0 \\
Sensation & & \\
Absent & 11 & 36.7 \\
Dysthesia & 7 & 23.3 \\
Intact & 12 & 40.0 \\
\hline
\end{tabular}


Table 2 Results of nerve conduction studies and electromyography

\begin{tabular}{llll}
\hline Measured parameters & & $\begin{array}{l}\text { Number of } \\
\text { nerves }\end{array}$ & Percentage (\%) \\
\hline CMAP & Absent & 19 & 63.3 \\
& Reduced & 11 & 36.7 \\
SNAP & Absent & 23 & 76.7 \\
& Normal & 4 & 13.3 \\
& Reduced & 3 & 10.0 \\
Denervation potentials & Absent & 10 & 33.3 \\
& Present & 20 & 66.7 \\
MUPs & Absent & 14 & 46.7 \\
& Neurogenic & 16 & 53.3
\end{tabular}

CMAP compound muscle action potential, SNAP sensory nerve action potential, MUPs motor unit potentials

Fourteen nerves (40\%) showed complete axonal loss (neurotmesis), whereas 16 nerves (60\%) showed partial axonal loss (axonotmesis). The shape and continuity of the examined nerves by US are demonstrated in Table 3. The types of injury and shapes of the injured nerve by US are shown in Table 4.

The role of US in the diagnosis of nerve injuries was classified according to whether US supported the diagnosis done by electrodiagnostic studies (EDX) or not into "contributive", when the US supported the diagnosis (this group included 20 nerves; 66.67\%) and "non-contributive", when the US did not support the diagnosis (this group included 10 nerves; 33.33\%).

The relation between the diseased muscle power and the compound muscle action potential (CMAP) amplitude is illustrated in Fig. 1.

The correlation between the duration of injury and denervation potentials, morphology of motor unit potentials (MUPs), and shape of the injured nerve by US is demonstrated in Table 5.

The correlation between the amplitude of the CMAP and continuity of the nerve by US is shown in Table 6 .

The correlation between the diagnosis of nerve injury by EDX and by high-resolution US is shown in Table 7 .

Table 3 Shape and continuity of the examined nerves by ultrasound

\begin{tabular}{lll}
\hline & Number of injured nerves & Percentage (\%) \\
Shape of nerve & & \\
\hline Fibrosis & 11 & 36.7 \\
Fusiform & 11 & 36.7 \\
Neuroma & 8 & 26.6 \\
Continuity & & \\
Continuous & 14 & 46.7 \\
Discontinuous & 16 & 53.3 \\
\hline
\end{tabular}

The sensitivity of US in confirming the diagnosis of complete nerve injury was $75 \%$. The specificity of US in the differentiation between complete and partial nerve injury was $61.1 \%$. The accuracy (diagnostic effectiveness) of US was $66.67 \%$.

\section{Discussion}

Traumatic peripheral nerve injuries are common in clinical practice. The history, neurological examination, and electrodiagnostic tests are generally used to diagnose the cause. Aside from neurophysiological assessment, highresolution US provides an increasing amount of complementary morphological information about nerves and their surrounding tissues [2].

Our study aimed at evaluating the role of US compared to EDX in nerve injuries. In our cases, the most commonly injured nerve was the ulnar nerve (36.67\%). This went in accordance with Adiguzel and colleagues [4] who explained the ulnar nerve as the largest unprotected nerve in the body; it is entirely subcutaneous and lacks overlying protective osseous or muscular structures.

The most common cause of peripheral nerve injuries in the present study was cut injury by sharp objects (66.7\%). This went in accordance with Uzun and colleagues [5], whereas Kouyoumdjian and colleagues [6] stated that the most common cause of peripheral nerve injuries was vehicular accidents.

In our study, muscle power was $\geq 2$ in muscles supplied by the affected nerves in $26.3-72.7 \%$ of nerves with decreased or absent CMAP, respectively. Şahin and colleagues [7] examined 50 nerves with traumatic nerve injuries to the wrists and found the same findings in 75$79 \%$ of patients with decreased or absent CMAP, respectively. This was explained by the fact that hand function requires the combined action of different muscles. EDX obtained from only one muscle could not be attributed to the overall function.

Upon combining EMG examination, we could detect denervation potentials in the form of fibrillation potentials and positive sharp waves at rest in the affected muscles of the injured nerves in $66.7 \%$ of nerves. Campbell [8] and Robinson [9] stated that with motor axonal loss, fibrillation potentials and positive sharp waves appear after 10-14 days in muscles near the injury site and after 3-4 weeks in more distal muscles and these potentials are recorded in the presence of even small degrees of axon loss.

With voluntary muscle activation, we detected abnormal neurogenic MUPs in 53.3\% of nerves. These are explained by collateral sprouting following incomplete axonal loss. The surviving motor axons give off collateral sprouts from the nerve terminals near the muscle fibers that have lost their innervation to reinnervate muscle 
Table 4 Type of injury and shape of the injured nerve by ultrasound

\begin{tabular}{|c|c|c|c|c|c|c|}
\hline \multirow[b]{3}{*}{ Type of Injury } & \multicolumn{6}{|c|}{ Shape of nerve } \\
\hline & \multicolumn{2}{|l|}{ Fibrosis } & \multicolumn{2}{|c|}{ Fusiform } & \multicolumn{2}{|c|}{ Neuroma } \\
\hline & Count & Percentage (\%) & Count & Percentage (\%) & Count & Percentage (\%) \\
\hline Compression & 0 & 0.00 & 1 & 100.00 & 0 & 0.00 \\
\hline Cut injury & 8 & 40.00 & 6 & 30.00 & 6 & 30.00 \\
\hline Fracture & 1 & 50.00 & 0 & 0.00 & 1 & 50.00 \\
\hline Post-operative & 1 & 50.00 & 1 & 50.00 & 0 & 0.00 \\
\hline Traction injury & 1 & 20.00 & 3 & 60.00 & 1 & 20.00 \\
\hline
\end{tabular}

fibers within a matter of days to weeks. As remodeling continues, the surviving MUAPs develop complexity with an increased number of turns evolving into polyphasia [8].

There were no MUPs detected in $46.7 \%$ of nerves, as the nerve would be non-excitable distal to the injury with electrophysiologically complete lesion [8].

According to NCS and EMG findings, we classified nerve injuries into partial axonal loss (60\%) and complete axonal loss (40\%), whereas Padua and colleagues [10] studied 112 nerve lesions in 98 patients and classified nerve injuries according to EDX into pure conduction block (7.1\%), partial axonal loss (59.8\%). and complete axonal loss (33.1\%). This could be due to higher number of participants in their study.

Ultrasound does not visualize the axons, myelin, and endoneurium but clearly recognizes the fascicles, perineurium, and epineurium. Based on the altered echogenicity of these three components, experts have tried to identify some of the peripheral nerve injury grades with US [11].

In this study, nerve injuries were divided by highresolution US into three groups; edematous swelling in the nerve; fusiform in shape $(36.7 \%)$; increased echogenicity inside the nerve; fibrosis $(36.7 \%)$ or increased nerve caliber and hyperechogenic internal structure; and neuroma (26.6\%). US also detected continuous nerves in $46.7 \%$ and discontinuous nerves in $53.3 \%$ of nerves. Koenig and colleagues [12] divided the findings of nerve injuries by US into five groups: normal, epineural fibrosis, intraneural fibrosis, neuroma/partial neuroma, and transection, whereas Extremite and colleagues [13] examined 36 patients with nerve injuries in the upper limbs and showed excellent capability in determining the type of injury, detection of proximal and distal nerve stump, foreign particles, stump neuroma, and perilesional excessive scar tissue formation.

We found no statistically significant difference between duration of injury and appearance of denervation potentials, morphology of MUPs, or shape of the injured nerve by US. This could be explained by the narrow range of the duration of injury (20-60 days). However, Campbell [9] reported that the electrodiagnostic picture depends on the time elapsed between the injury and the evaluation, and this point is an important one to be highlighted by clinicians and neurophysiologists during examination.

Tsukamoto and colleagues [14] reported that most articles focused on traumatic nerve injuries and did not address a correlation between US and EDX. So, we tried to highlight this point in our study. We concluded that there was no statistically significant difference between

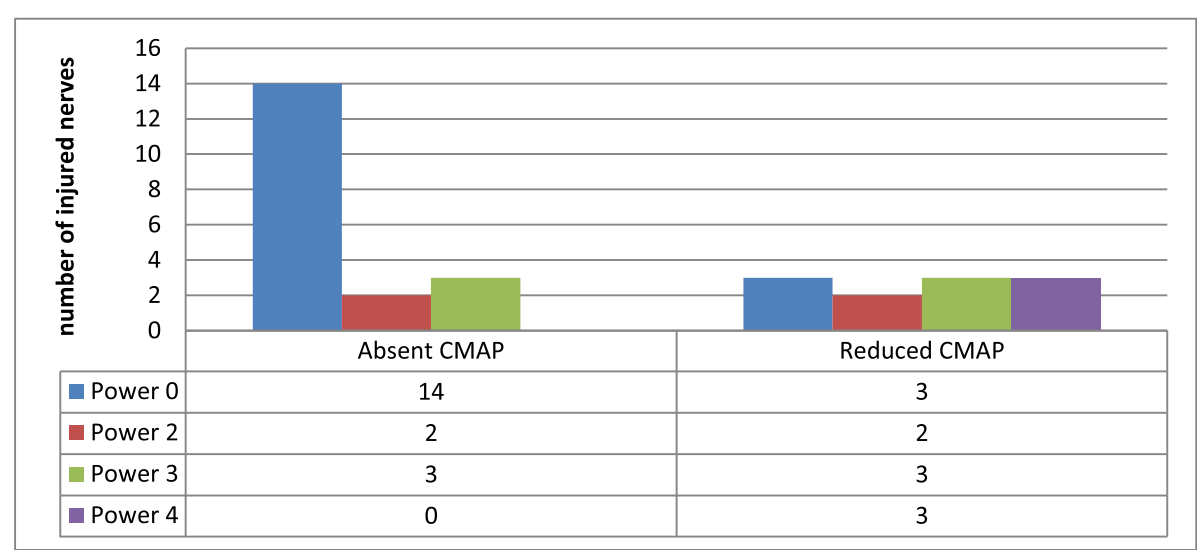

Fig. 1 Relationship between compound muscle action potential amplitude and power of the supplied muscles 
Table 5 Correlation between duration of injury and denervation potentials, morphology of MUPs, and shape of the injured nerve by ultrasound

\begin{tabular}{|c|c|c|c|c|}
\hline & & \multicolumn{2}{|c|}{$\begin{array}{l}\text { Duration of injury } \\
\text { (days) }\end{array}$} & \multirow[b]{2}{*}{$p$ value } \\
\hline & & Mean & SD & \\
\hline \multirow[t]{2}{*}{ Denervation potentials } & Absent $(n=10)$ & 51.1 & 12.1 & 0.212 \\
\hline & Present $(n=20)$ & 45.1 & 11.9 & \\
\hline \multirow[t]{2}{*}{ MUPS } & Absent $(n=14)$ & 47 & 13 & 0.37 \\
\hline & Neurogenic $(n=16)$ & 48 & 12 & \\
\hline \multirow[t]{3}{*}{ Shape of nerve } & Fibrosis $(n=11)$ & 47 & 13 & 0.826 \\
\hline & Fusiform $(n=11)$ & 49 & 8 & \\
\hline & Neuroma $(n=8)$ & 45 & 17 & \\
\hline
\end{tabular}

$p \leq 0.05$ is considered statistically significant

MUPs motor unit potentials, SD standard deviation

amplitude of CMAP and continuity of the nerve by US $(p=0.156)$. This goes in agreement with Campbell [8] who stated that the CMAP distal to the injury decreases in amplitude in "rough" proportion to the degree of axonal loss.

We found a statistically significant difference between diagnosis of nerve injury done by EDX and by highresolution US regarding continuity of the nerve $(p=$ 0.05). Also, Lauretti and colleagues [11] found that complete anatomical nerve interruption as described by Sunderland grade V can be quite easily recognized by US, while internal nerve damage with the epineurium in continuity (Sunderland grades III and IV) is more difficult to interpret.

The accuracy of US in detecting nerve continuity in our study was $66.67 \%$. This was a bit less than the value obtained by Toia and colleagues [15] where it was $72.2 \%$.

The sensitivity of US in detecting nerve continuity in our study was $75 \%$, while it was $51.35 \%$ in the study done by Padua and colleagues [10] in which they

Table 6 CMAP amplitude and continuity of the injured nerve by ultrasound

\begin{tabular}{|c|c|c|c|c|c|}
\hline \multirow[b]{3}{*}{ CMAP } & \multicolumn{4}{|c|}{ Continuity by ultrasound } & \multirow[b]{3}{*}{$p$ value } \\
\hline & \multicolumn{2}{|c|}{ Continuous } & \multicolumn{2}{|c|}{ Discontinuous } & \\
\hline & Count & Percentage (\%) & Count & Percentage (\%) & \\
\hline Absent & 7 & 50.0 & 12 & 75.0 & 0.156 \\
\hline Reduced & 7 & 50.0 & 4 & 25.0 & \\
\hline $\begin{array}{l}\text { Diagnosis } \\
\text { by EDX }\end{array}$ & & & & & $p$ value \\
\hline Complete & 3 & 21.40 & 9 & 56.30 & $0.05^{*}$ \\
\hline Partial & 11 & 78.60 & 7 & 43.70 & \\
\hline
\end{tabular}

*statistically significant $P$ value

$p \leq 0.05$ is considered statistically significant

$C M A P$ compound muscle action potential, EDX electrodiagnostic studies, SD

standard deviation
Table 7 Diagnosis of nerve injury by electrophysiology and by ultrasound

\begin{tabular}{|c|c|c|c|c|c|}
\hline \multirow[b]{3}{*}{$\begin{array}{l}\text { Diagnosis by } \\
\text { electrophysiology }\end{array}$} & \multicolumn{4}{|c|}{ Continuity by ultrasound } & \multirow[b]{3}{*}{$p$ value } \\
\hline & \multicolumn{2}{|c|}{ Continuous } & \multicolumn{2}{|c|}{ Discontinuous } & \\
\hline & Count & $\begin{array}{l}\text { Percentage } \\
(\%)\end{array}$ & Count & $\begin{array}{l}\text { Percentage } \\
(\%)\end{array}$ & \\
\hline Complete & 3 & 21.40 & 9 & 56.30 & 0.05 \\
\hline Partial & 11 & 78.60 & 7 & 43.70 & \\
\hline
\end{tabular}

examined 37 nerves diagnosed as complete injury and by US only 19 nerves appeared discontinuous, whereas the specificity of US in differentiating between complete and partial nerve injury in our study was $61.1 \%$, and, to our knowledge, there was not a similar test found in the literature.

\section{Conclusion}

Our study concluded that electrophysiological studies are irreplaceable in the evaluation of nerve injuries and that US can be used only as a complementary diagnostic tool. We also found that US can be of value in visualization of the morphological abnormalities associated with nerve injuries, including swelling, scar tissue, and neuroma formation, especially in cases with complete axonal lesion, a finding that could not be evaluated by EDX.

\section{Limitations of the study}

The limitation of the study is the relatively small number of patients, besides having one female patient and one injured peroneal nerve in our sample.

\section{Supplementary information}

Supplementary information accompanies this paper at https://doi.org/10. 1186/s41983-020-00166-3.

Additional file 1. MRC scale of muscle power.

\section{Abbreviations}

CMAP: Compound muscle action potential; CSA: Cross-sectional area; EDX: Electrodiagnostic studies; EMG: Electromyography; MRC scale: Medical Research Council scale; MUPs: Motor unit potentials; NCS: Nerve conduction studies; SNAP: Sensory nerve action potential; US: Ultrasonography/ ultrasound

\section{Acknowledgements}

Not applicable

\section{Informed consent}

Written informed consent was obtained from every participant involved in this research prior to the conduct of any study-related activities. All data were confidential and were not used outside the study. The patients had the rights to withdraw from the study at any time without giving any reason. All the cost of the investigations was afforded by the researchers.

\section{Authors' contributions}

All authors contributed to the research idea and methodology. M.S. contributed to the data collection. H.E. and A.L. analyzed and interpreted the 
data. N.E. completed the first draft of the article. All authors contributed to drafting and revising the manuscript. All authors read and approved the final manuscript.

\section{Funding}

No funding sources for this research has to be declared (financial or nonfinancial). Funding was provided by the researchers.

\section{Availability of data and materials}

Not applicable

\section{Ethics approval and consent to participate}

The study was approved by the ethical committee of the Department of Neurology, Faculty of Medicine, Cairo University, on the 15th of October 2018, but Cairo University does not provide the approval reference number. All procedures performed in the study were in accordance with the ethical standards of the institutional research committee and with the 1964 Helsinki Declaration and its later amendments.

\section{Consent for publication}

Not applicable

\section{Competing interests}

The authors declare that they have no competing interests.

\section{Author details}

${ }^{1}$ Clinical Neurophysiology Unit, Faculty of Medicine, Cairo University, Cairo, Egypt. ${ }^{2}$ Department of Neurology, Faculty of Medicine, Cairo University, Cairo, Egypt. ${ }^{3}$ Kasr Al Ainy, Faculty of Medicine, Cairo University, 52 Mosadak Street, Dokki, Giza 12611, Egypt.

Received: 7 January 2020 Accepted: 18 February 2020

Published online: 05 March 2020

\section{References}

1. Zhu J, Liu F, Li D, Shao J, Hu B. Preliminary study of the types of traumatic peripheral nerve injuries by ultrasound. Eur Radiol. 2011;21(5):1097-101.

2. Mallon S, Starcevic V, Rheinboldt M, Petraszko A. Sonographic evaluation of peripheral nerve pathology in the emergency setting. Emerg Radiol. 2018; 25(5):521-31.

3. Bignotti B, Tagliafico A, Martinoli C. Ultrasonography of peripheral nerves: anatomy and pathology. Ultrasound Clin. 2014;9(3):525-36.

4. Adiguzel E, Yaşar E, Tecer D, Güzelküçük Ü, Taşkaynatan MA, Kesikburun S, et al. Peripheral nerve injuries: long term follow-up results of rehabilitation. J Back Musculoskelet Rehabil. 2016;29(2):367-71

5. Uzun N, Tanriverdi T, Savrun FK, Kiziltan ME, Sahin R, Hanimoglu H, et al. Traumatic peripheral nerve injuries: demographic and electrophysiologic findings of 802 patients from a developing country. J Clin Neuromuscul Dis. 2006;7(3):97-103.

6. Kouyoumdjian JA, Graça CR, Ferreira FM. Peripheral nerve injuries: a retrospective survey of 1124 cases. Neurol India. 2017;65(3):551.

7. Şahin F, Atalay NŞ, Akkaya N, Ercidoğan Ö, Başakçı B, Kuran B. The correlation of neurophysiological findings with clinical and functional status in patients following traumatic nerve injury. J Hand Surg Eur Vol. 2014;39(2): 199-206.

8. Campbell WW. Evaluation of peripheral nerve injury. Eur J Pain Supplements. 2009;3(2):37-40.

9. Robinson LR. How electrodiagnosis predicts clinical outcome of focal peripheral nerve lesions. Muscle Nerve. 2015;52(3):321-33.

10. Padua L, Di Pasquale A, Liotta G, Granata G, Pazzaglia C, Erra C, et al. Ultrasound as a useful tool in the diagnosis and management of traumatic nerve lesions. Clin Neurophysiol. 2013;124(6):1237-43.

11. Lauretti L, D'Alessandris QG, Granata G, Padua L, Roselli R, Di Bonaventura R, et al. Ultrasound evaluation in traumatic peripheral nerve lesions: from diagnosis to surgical planning and follow-up. Acta Neurochirurgica. 2015; 157(11):1947-51.

12. Koenig RW, Schmidt TE, Heinen PG, Wirtz CR, Kretschmer T, Antoniadis G, et al. Intraoperative high-resolution ultrasound: a new technique in the management of peripheral nerve disorders. J Neurosurg. 2011;114(2):514-21.

13. Extremite Ü, Sinir $P$, Cerrahi $Y$, Intraoperatif T, Kullanlmas U. Ultrasound examination in the surgical treatment for upper extremity peripheral nerve injuries: Part I. In: Çokluk C, Aydin K, editors. Turkish Neurosurgery, vol. 17. Turkey: Samsun; 2007. p. 277-82.

14. Tsukamoto H, Granata G, Coraci D, Paolasso I, Padua L. Ultrasound and neurophysiological correlation in common fibular nerve conduction block at fibular head. Clin Neurophysiol. 2014;125(7):1491-5.

15. Toia F, Gagliardo A, D’Arpa S, Gagliardo C, Gagliardo G, Cordova A. Preoperative evaluation of peripheral nerve injuries: What is the place for ultrasound? J Neurosurg. 2016;125(3):603-14.

\section{Publisher's Note}

Springer Nature remains neutral with regard to jurisdictional claims in published maps and institutional affiliations.

\section{Submit your manuscript to a SpringerOpen ${ }^{\circ}$ journal and benefit from:}

- Convenient online submission

- Rigorous peer review

- Open access: articles freely available online

- High visibility within the field

- Retaining the copyright to your article

Submit your next manuscript at $\boldsymbol{\nabla}$ springeropen.com 